\title{
Cellusim: Un simulador 3D en entorno videojuego para la docencia del laboratorio de cultivos celulares
}

\author{
Daniel Monléon $^{\mathrm{a}, *}$, Javier Megias ${ }^{\mathrm{a}}$, Teresa San Miguel $^{\mathrm{a}}$, Consuelo Borrás ${ }^{\mathrm{b}}$, Rosario Gil- \\ Benso $^{a}$, Concha López-Ginés ${ }^{a}$ \\ àpepartamento de Patología, Universitat de Valencia, bepartamento de Fisiología, Universitat de \\ Valencia, *Autor de correspondencia: daniel.monleon@uv.es
}

\begin{abstract}
Cell cultures allow the maintenance of living cells outside the body. This technique is fundamental to study the biological, biochemical and physiological properties of cells and can be used as an experimental model in vitro in the field of biomedical research. The teaching in the laboratory of this technique presents numerous difficulties at a practical, logistical and economic level. On the other hand, the learning of cell culture protocols is an important part of the student's training in Cell Biology. Based on the routine practices carried out within a cell culture laboratory, we have developed the virtual 3D simulator of a cell culture laboratory "Cellusim". In "Cellusim" you can perform basic tasks of the cell culture of an established cell line of your own (Mel-RC08, Gil-Benso et al., 2012). To make Cellusim more attractive and intuitive to students, it has been developed in the Unity graphic environment, commonly used for the development of video games. The system includes the simulator in Unity, a mysql server with users, passwords and logs and a web of help and explanatory videos. In the simulator the student can virtually execute the essential tasks that are performed in a cell culture laboratory, such as thawing cells, seeding the cells, preparing and changing culture media and making cell subcultures. Cellusim is a training tool that allows users to discover the basics of cell culture techniques in a simple and fast way and without the economic costs or time consumption derived from doing the same work in a real laboratory. In order to evaluate the students' learning, Cellusim can be executed in training mode and in evaluation mode, allowing the student to perform all the processes as many times as necessary to become familiar with the protocols and when be able to execute them in evaluation mode. In evaluation mode, Cellusim records student errors in order to score the acquired training. In this communication we present the Cellusim project and the results of the first experiences with volunteer students of Master's Degrees in the School of Medicine.
\end{abstract}

Keywords: cell biology, virtual laboratory, 3D simulator, teaching health sciences, unity, video games for teaching

\section{Resumen}

Los cultivos celulares permiten el mantenimiento de células vivas fuera del organismo. Esta técnica es fundamental para estudiar las propiedades biológicas, bioquímicas y fisiológicas de las células y puede ser utilizada como 
modelo experimental in vitro en el ámbito de la investigación biomédica. La enseñanza en el laboratorio de esta técnica presenta numerosas dificultades a nivel práctico, logístico y económico. Por otra parte, el aprendizaje de los protocolos del cultivo celular resultan una parte importante de la formación del alumno de Biología Celular. Basándonos en las prácticas rutinarias llevadas a cabo dentro de un laboratorio de cultivos celulares, hemos desarrollado el simulador virtual 3D de un laboratorio de cultivos celulares "Cellusim". En "Cellusim" se pueden realizar tareas básicas del cultivo celular de una línea celular establecida propia (Mel-RC08, Gil-Benso y cols., 2012). Para hacer Cellusim más atractivo e intuitivo a los alumnos, ha sido desarrollado en el entorno gráfico Unity, utilizado habitualmente para el desarrollo de videojuegos. El sistema incluye el simulador en Unity, un servidor mysql con usuarios, contraseñas y registros y una web de ayuda y videos explicativos. En el simulador el alumno puede ejecutar de modo virtual las tareas esenciales que se realizan en un laboratorio de cultivos celulares, tales como la descongelación de células, el sembrado de las células, la preparación y el cambio de medios de cultivo y el subcultivo celular o técnica de doblaje. Cellusim es una herramienta formativa que permite a los usuarios descubrir los fundamentos de las técnicas básicas de cultivo celular de una manera sencilla, rápida y sin los costes económicos ni el consumo de tiempo derivados de realizar el mismo trabajo en un laboratorio real. Para poder evaluar el aprendizaje de los alumnos, Cellusim puede ser ejecutado en modo entrenamiento y en modo evaluación, permitiendo que el alumno realice todos los procesos las veces que sea necesario para familiarizarse con los protocolos y que cuando esté en condiciones pueda ejecutarlas en modo evaluación. En modo evaluación, Cellusim registra los errores del alumno para poder puntuar la formación adquirida. En esta comunicación presentamos el proyecto Cellusim y los resultados de las primeras experiencias con alumnos voluntarios de Master de la Facultad de Medicina.

Palabras clave: biología celular, laboratorio virtual, simulador 3D, docencia en ciencias de la salud, unity, videojuegos para docencia

\section{Introducción}

Se entiende por cultivo celular al conjunto de técnicas que permite el mantenimiento de células vivas fuera de un organismo, preservando en la medida de lo posible sus propiedades fisiológicas, bioquímicas y genéticas. Las condiciones ambientales controladas que se aplican para el mantenimiento de un cultivo celular reciben el nombre de condiciones in vitro, término latino que alude al uso inicial de recipientes de vidrio como soporte para la vida de las células aisladas del organismo.

En la actualidad, los cultivos celulares son muy utilizados en el ámbito de investigación biomédica, debido a sus múltiples aplicaciones entre las que destacan: la fecundación in vitro,

(cc) BY-NC-ND 2018, Universitat Politècnica de València

Congreso IN-RED (2018) 
terapia génica, estudios farmacológicos, fabricación de vacunas, estudios citogenéticos, microbiología, cartografía génica, tratamiento de quemados, obtención de anticuerpos monoclonales e investigación básica en biología molecular.

La Unidad de Biología del Departamento de Patología de la Universidad de Valencia imparte una práctica sobre Cultivos Celulares en las asignaturas de Biología de los grados de Medicina, Odontología, Podología e Ingeniería Biomédica. En esta práctica se abordan los fundamentos, técnicas y aplicaciones de los cultivos celulares, y se observan preparaciones microscópicas de diversos cultivos celulares; de procedencia animal y de células tumorales humanas.

Este tipo de docencia, pese a tener un éxito pedagógico contrastado, adolece de una limitación principal: que los alumnos no pueden acceder a las instalaciones de un laboratorio de cultivos celulares real, ni trabajar con células vivas. Esta limitación implica que el conocimiento adquirido sobre las técnicas de mantenimiento de cultivos celulares sea únicamente teórico y, por tanto, alejado de la realidad del laboratorio.

Por otro lado, se descarta plantear una práctica de laboratorio real. Esto se debe a cuatro limitaciones insalvables: (a) el elevado número de alumnos matriculados en las asignaturas de Biología, (b) el tiempo limitado disponible para las prácticas, (c) el tamaño reducido de los laboratorios de cultivos celulares y (d) el gasto de material específico de laboratorio de alto coste.

Por las razones expuestas, se requiere la fabricación de una herramienta pedagógica que mejore la docencia en las técnicas de cultivo celular, sin suponer un elevado coste, ni un exceso en las horas de docencia establecidas.

\section{Objetivos}

El objetivo general del presente trabajo es el desarrollo de nuevos métodos de aprendizaje de los protocolos de cultivos celulares para acercar al alumno al entorno y complejidad de esta técnica. En concreto los objetivos particulares han sido:

1) Desarrollar el simulador virtual "Cellusim"; una herramienta pedagógica que reproduce el trabajo rutinario de un laboratorio de cultivos celulares. El uso del simulador permitirá un acercamiento por parte de los usuarios al trabajo de laboratorio, sin el elevado coste que supondría el mismo trabajo en un laboratorio real. "Cellusim” contribuye a la formación de nuevos investigadores y de alumnos pertenecientes a grados de carácter biomédico o sanitario.

2) Dar a "Cellusim" un enfoque docente con el fin de evaluar de una manera objetiva los conocimientos del alumno de grado sobre el manejo virtual de cultivos celulares, gracias al sistema de penalización de errores incorporado.

\section{El simulador Cellusim}

Se accede al simulador ejecutando el programa instalado de modo local. Tras ello se muestra la pantalla inicial que muestra el acceso al sistema virtual en la que se debe ingresar el correo electrónico y contraseña del usuario que fue previamente registrado en la página web de administración. 


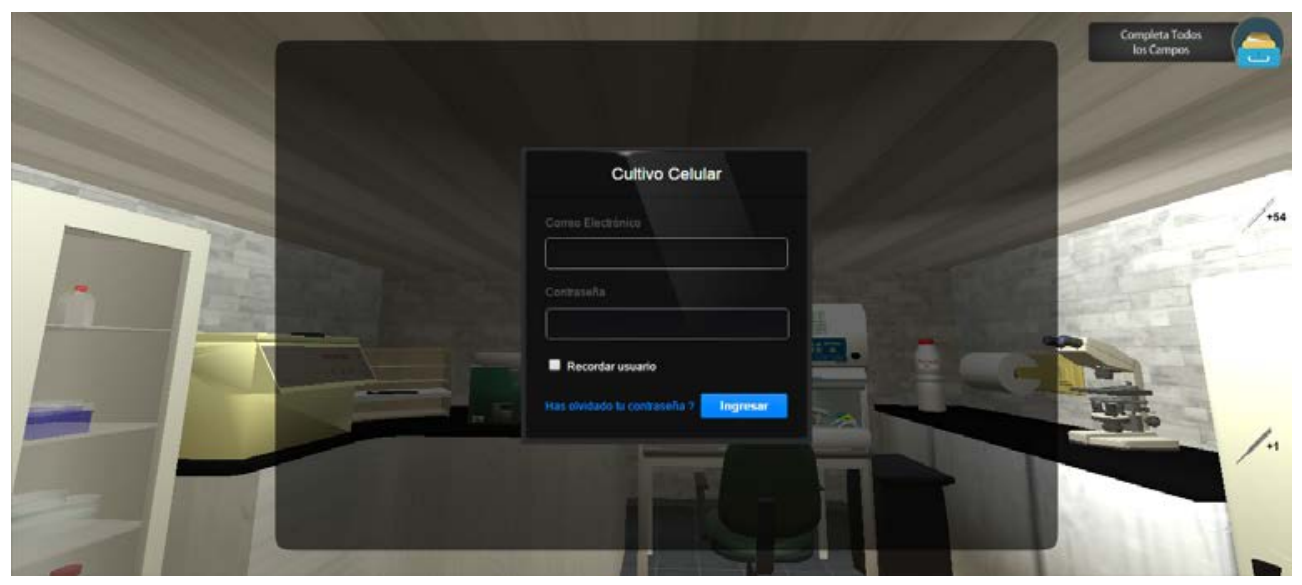

Figura 1: Ventana de acceso al sistema virtual de cultivo celular

Dentro del sistema virtual, tal y como se realiza en el laboratorio real, se tendrá que configurar la Temperatura y el 『CO $\rrbracket \_2$ de la incubadora que es el paso fundamental para el resto de actividades en el cultivo celular.

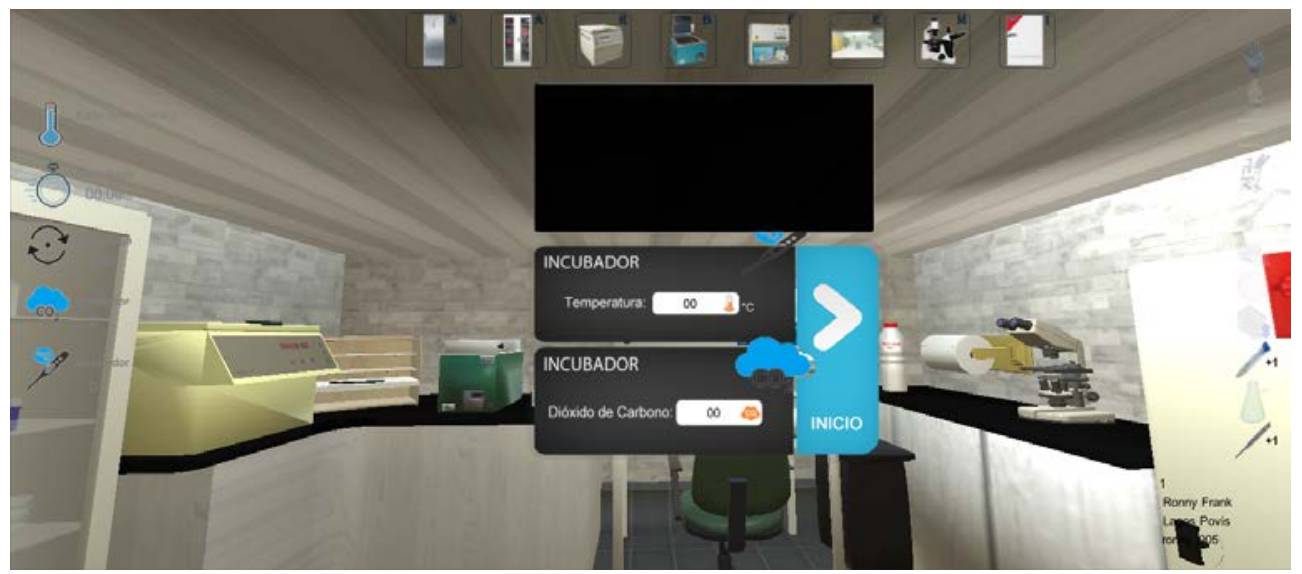

Figura 2: Establecer la Temperatura y el 『CO』_2 de la incubadora.

A partir de aquí, nos encontramos en medio del laboratorio y podemos acceder a diferentes estaciones de trabajo (congelador, nevera, microscopia, estufa, campana de cultivos, centrífuga, etc) cada una con sus controladores y protocolos de trabajo definidos. En el laboratorio el alumno tiene que realizar 4 tareas básicas del laboratorio de cultivos con su protocolo de pasos definidio y explicado previamente en clase (descongelado de células, sembrado de células, cambio de medio de cultivo y realización de un subcultivo o pase). A modo ilustrativo exponemos los pasos a seguir para las tareas a realizar. 


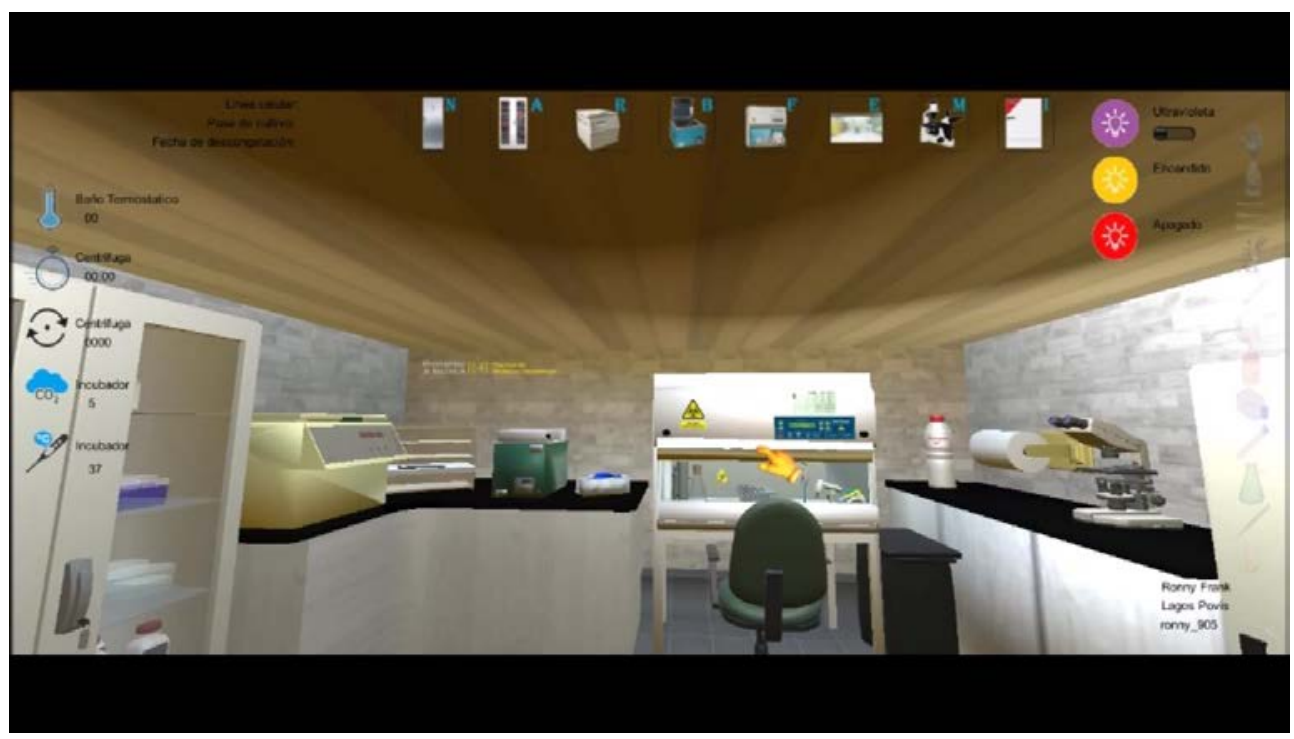

Figura 3. Visión general del laboratorio Cellusim con las diferentes estaciones de trabajo en la parte superior a las que se puede acceder mediante el ratón o mediante atajos de teclado.

Para el proceso de descongelación de las células contenidas en un criovial y sembrado de las mismas se realizan los siguientes pasos: 1) Ponerse guantes de látex antes de comenzar a trabajar; 2) Poner en marcha la cabina de flujo laminar y limpiarla con alcohol al 70\%; 3) Establecer la temperatura del baño termostático a $37^{\circ} \mathrm{C}$; 4) Obtener el medio de cultivo de la nevera y colocar en el baño termostático; 5) Obtener el criovial con células congeladas y colocar en el baño termostático, hasta que el medio de congelación con la suspensión celular se descongele completamente; 6) Llevar el medio de cultivo y el criovial del baño termostático a la cabina de flujo laminar; 7) Añadir $5 \mathrm{ml}$ de medio de cultivo a un tubo estéril de $15 \mathrm{~mL}$; 8) Añadir el contenido del criovial (suspensión celular) al tubo estéril; 9) Centrifugar las células a 1200 rpm durante 5 minutos; 10) Eliminar el sobrenadante del tubo por medio de una pipeta Pasteur y la bomba de vacío; 11) Resuspender el precipitado celular y transferir a un frasco de cultivo. Añadir $5 \mathrm{ml}$ de medio de cultivo en el frasco; 12) Observar las células en el microscopio óptico invertido; 13) Guardar las células en el incubador. 


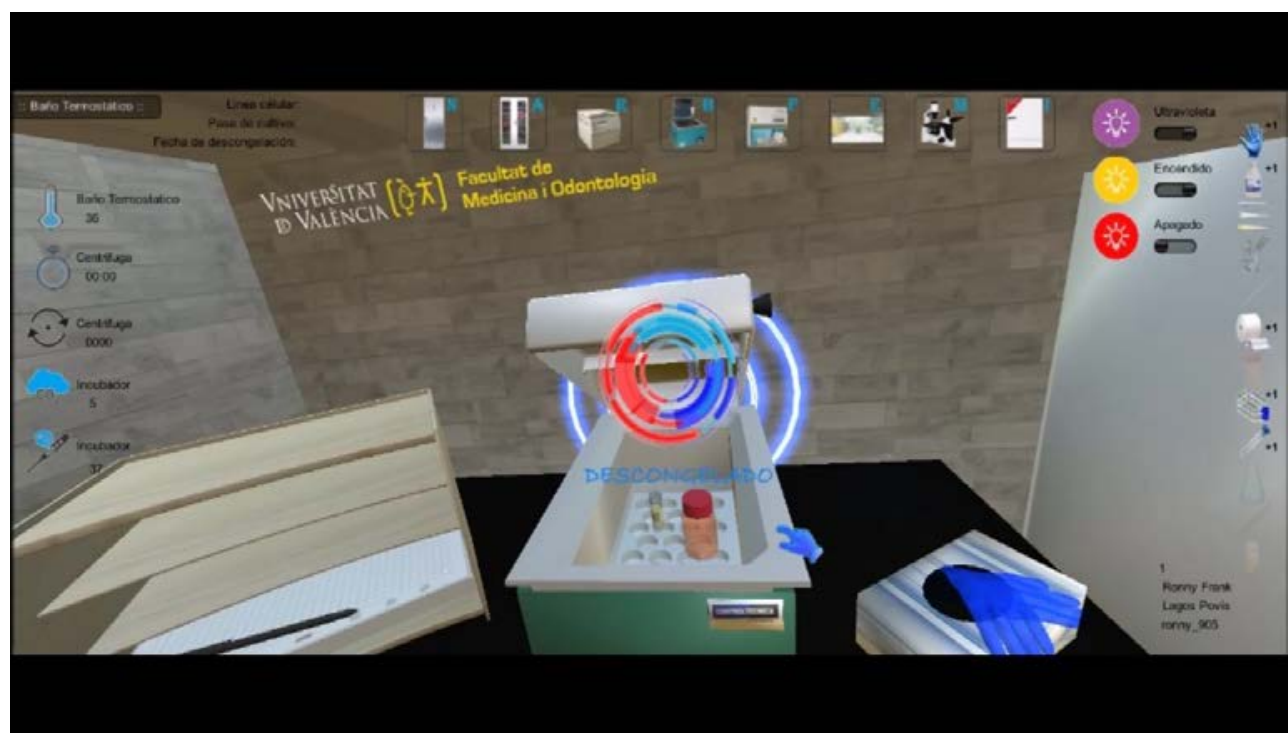

Figura 4. Descongelación de las células en el baño termostático. El proceso en el laboratorio real lleva alrededor de 15 minutos pero en el simulador se ha acelerado a algunos segundos y se indica el progreso del tiempo mediante avance de barras circulares.

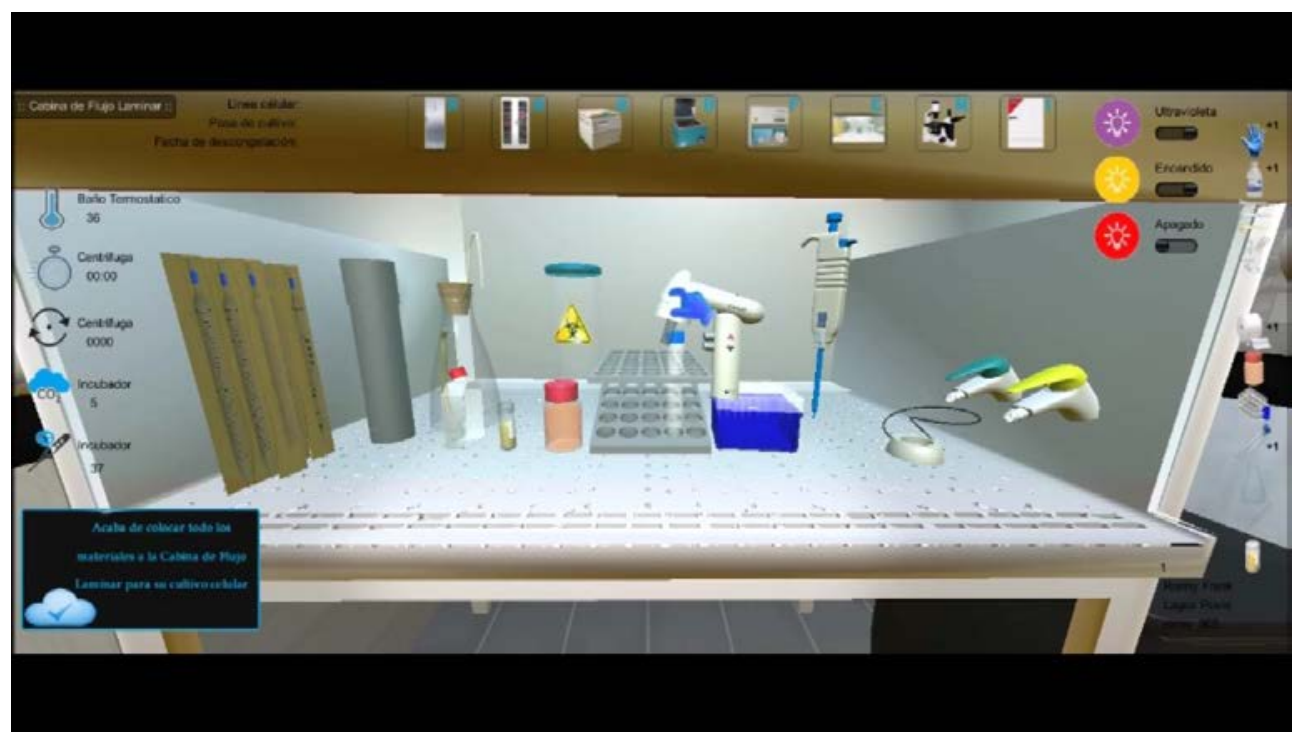

Figura 5. Visión de la cabina de cultivos celulares de Cellusim en que se pueden apreciar los distintos elementos e instrumental para realizar las operaciones especificadas en el protocolo de trabajo. Una nota de aviso en la esquina inferior izquierda informa al alumno cuando se alcanzan hitos relevantes en el protocolo. En la esquina superior derecha se encuentran los controles de la cabina. En el lateral izquierdo el alumno tiene permanentemente la información sobre el estado de los diferentes sistemas del laboratorio (baño termostático, estufa, etc).

Para la realización del cambio de medio de cultivo los pasos a seguir son los siguientes: 1) Ponerse guantes de látex antes de comenzar a trabajar; 2) Poner en marcha la cabina de flujo 
laminar y limpiarla con alcohol al 70\%; 3) Establecer la temperatura del baño termostático a $37^{\circ} \mathrm{C}$; 4) Obtener el medio de cultivo de la nevera y colocar en el baño termostático; 5) Sacar el frasco con las células del incubador; 6) Observar el estado de las células y su confluencia al microscopio óptico invertido; 7) Eliminar el medio de cultivo del frasco con una pipeta Pasteur y la bomba de vacío; 8) Añadir $5 \mathrm{~mL}$ de medio de cultivo completo al frasco; 9) Observar nuevamente las células al microscopio óptico invertido; 10) Depositar las células en el incubador.

Para el proceso de realización de un subcultivo celular o pase los pasos a seguir en el simulador son: 1)Ponerse guantes de látex antes de comenzar a trabajar; 2) Poner en marcha la cabina de flujo laminar y limpiarla con alcohol al 70\%; 3) Establecer la temperatura del baño termostático a $37^{\circ} \mathrm{C}$; 4) Obtener el medio de cultivo de la nevera y colocar en el baño termostático; 5) Sacar el frasco con las células del incubador; 6) Observar el estado de las células y su confluencia al microscopio óptico invertido; 7) Eliminar el medio de cultivo del frasco con una pipeta Pasteur y la bomba de vacío; 8) Lavar las células añadiendo $5 \mathrm{~mL}$ de PBS; 9) Eliminar el PBS por medio de una pipeta Pasteur y la bomba de vacío; 10) Añadir 2 $\mathrm{mL}$ de tripsina e incubar a 37oC durante 5 minutos; 11) Añadir $5 \mathrm{~mL}$ de medio completo al frasco y recoger la suspensión celular en un tubo estéril de $15 \mathrm{~mL}$; 12) Centrifugar las células a 1200 rpm durante 5 minutos; 13) Eliminar el sobrenadante del tubo por medio de una pipeta Pasteur y la bomba de vacío; 14) Resuspender el precipitado celular y transferir a dos frascos de cultivo. Añadir $5 \mathrm{ml}$ de medio de cultivo en cada frasco; 15) Observar las células en el microscopio óptico invertido; 16) Guardar las células en el incubador.

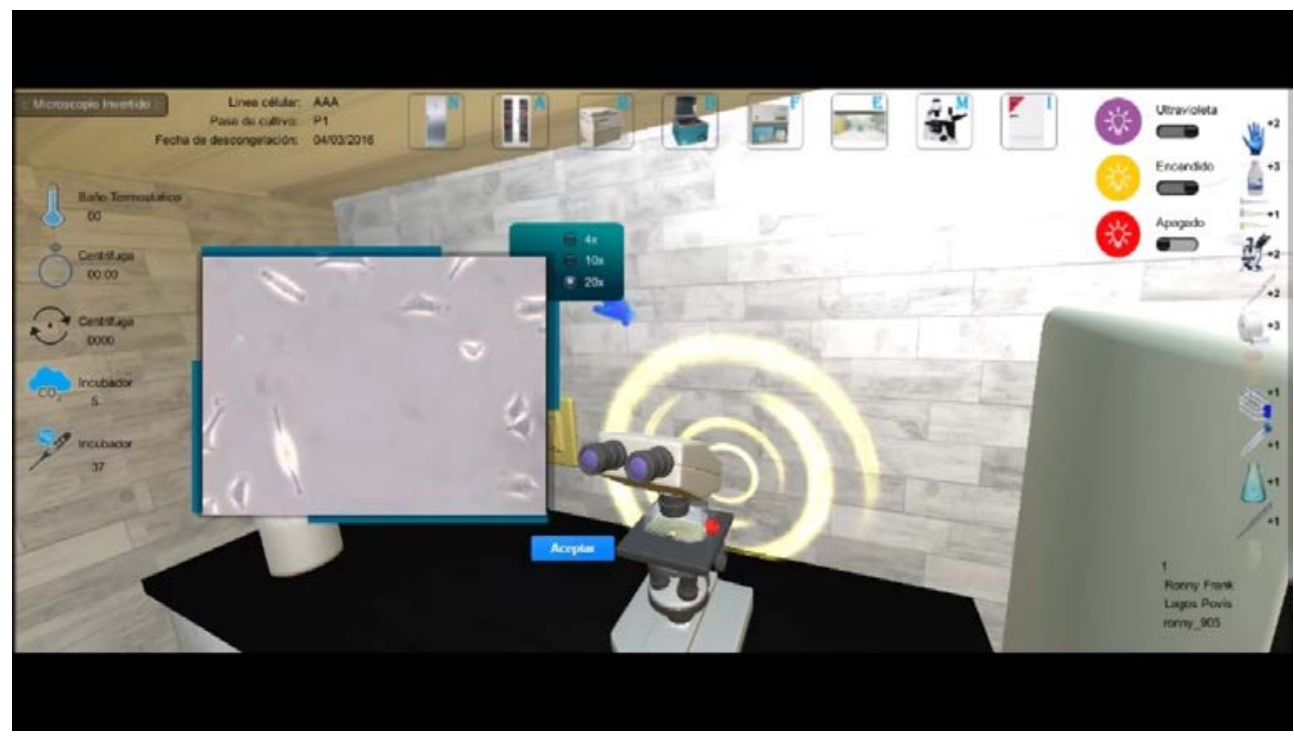

Figura 6. Observación de células en cultivo en el microscopia en el entorno del simulador Cellusim.

Durante la etapa en que el alumno utiliza el simulador en mod entrenamiento, el alumno se familiariza con la ubicación de los diferentes elementos en el laboratorio (viales, crioviales, pipetas, guantes, estaciones de trabajo, etc). A partir de ahí, el trabajo en este laboratorio 
virtual es mucho más fluido y el alumno puede pasar a ser evaluado cambiando el modo a evaluación.

El proceso completo dura alrededor de 20 minutos ya que los tiempos de crecimiento de las células y de operaciones largas como la descongelación o la centrifugación han sido reducidos a segundos. En el video del enlace http://www.uv.es/dmonleon/cellusim/videodemo.avi es posible observar todo el proceso. La sensación para el alumno es siempre la de estar participando en un videojuego interactivo 3D con lo que la motivación para el uso y aprendizaje es muy alta.

\section{Experiencia con los alumnos}

Los alumnos de diversos estudios de Máster en la Facultad de Medicina han mostrado interés en el simulador y lo han podido probar. La experiencia en general ha sio muy positiva e incluso algunos profesores e investigadores jefe de grupo han pedido acceso al simulador para que sus doctorandos y el personal que se va a iniciar en los cultivos celulares reales en entornos de investigación experimenten antes con el simulador para acelerar su cirva de aprendizaje. Tras estos ensayos voluntarios hemos recibido numerosas sugerencias de mejora (una libreta de laboratorio virtual que acompañe a las operaciones, barra de vida remanente que disminuya al cometer errores, etc) que esperamos incluir en la versión 2.0 del simulador.

\section{Conclusiones}

Cellusim es el primer simulador 3D construido con un motor de videojuegos para el aprendizaje de las técnicas de cultivos celulares y la evaluación de conocimientos del alumno. Existen otros simuladores con un fin parecido pero carecen de los componentes de ellusim más atractivos para los alumnos (entorno 3D, motor de videojuego, posibilidad de entrenamiento) y para los profesores (posibilidad de monitorización del alumno, posibilidad de evaluación interna en el simulador). Las primeras experiencias con voluntarios han superado en mucho nuestras expectativas y ha suscitado mucho interés tanto para la docencia en los grados relacionados con Ciencias de la Salud como en entornos de enseñanza postgrado y formación en investigación.

\section{Referencias}

Gil-Benso R, Monteagudo C, Cerdá-Nicolás M, Callaghan RC, Pinto S, Martínez-Romero A, Pellín-Carcelén A, San-Miguel T, Cigudosa JC, López-Ginés C. Characterization of a new human melanoma cell line with CD133 expression. Hum Cell. 2012 Jun; 25(2): 61-7.

(c) EY-NC-ND 2018, Universitat Politècnica de València

Congreso IN-RED (2018) 